\title{
The Usefulness of Employing an Electronic Traction Table to Determine Flexibility in Adolescent Idiopathic Scoliosis
}

\author{
Erman CEYHAN ${ }^{1}$, Onder Murat DELIALIOGLU ${ }^{2}$, Kenan BAYRAKCl${ }^{2}$, Bulent DAGLAR ${ }^{3}$, Alper DEVECI ${ }^{4}$, \\ Ugur GUNEL ${ }^{1}$ \\ ${ }^{1}$ Social Security Institution, General Directorate of Universal Health Insurance, Ankara, Turkey \\ ${ }^{2}$ Tiran American Hospital, Orthopaedics and Traumatology Clinic, Tiran, Albania \\ ${ }^{3}$ Guven Hospital, Orthopaedics and Traumatology Clinic, Ankara, Turkey \\ ${ }^{4}$ Ankara Numune Training and Research Hospital, Orthopaedics and Traumatology Clinic, Ankara, Turkey
}

\section{ABSTRACT}

AIM: The aim of the study was to develop new equipment for the assessment of the flexibility of the spine with different forces. This new system should provide a different perspective to adolescent idiopathic scoliosis (AIS) for the selection of fusion levels and surgical success.

MATERIAL and METHODS: Eighteen patients suffering from AIS who were scheduled to undergo posterior instrumented spinal fusion in our clinic were recruited in this study. The Electronic Traction Table (ETT) that was designed in our clinic was used to evaluate the radiogical and clinical parameters of the spine.

RESULTS: The significant prescriptive angle of major Cobb angles between postoperative angles were longitudinal traction and lateral pushing Cobb angles. Longitudinal traction and lateral pushing angles were more correlated with correction ratios. There was a significant difference between longitudinal traction minor Cobb angle, longitudinal traction lateral pushing minor Cobb angle and postoperative minor Cobb angles.

CONCLUSION: The deformity is needed to balance both tractional and rotational forces and useful technique to evaluate curve flexibility before the operation. Electronic traction table is a new device for determining preoperative flexibility with longitudinal traction and lateral pushing radiographs. It can be useful for choosing selective fusion levels at the proximal and distal end of the vertebral column.

KEYWORDS: Adolescent idiopathic scoliosis, Traction table, Fusion levels, Curve flexibility

\section{INTRODUCTION}

A dolescent idiopathic scoliosis (AIS) is a 3-dimensional spinal deformity that most commonly occurs during growth (1). The success of surgical management depends on the selection of fusion levels due to the importance of preserving motion segments $(11,19)$. The selection of the fusion levels is still a controversial issue $(3,6)$. Several preoperative planning methods have been described in the literature but surgical management is not always sufficiently addressed (18). When creating a template of the fusion levels, preoperative assessment of spinal flexibility is critical. Several techniques are referenced in the literature for assessing spinal flexibility (1), including suspension test, push traction films and traction radiographs $(2,8)$. However, no single equipment exists that offers comparable utility in all patients and positions.

This study aims to present a new piece of equipment developed for assessing spinal flexibility at different force levels, 
and to demonstrate its efficacy for the treatment of AIS. This new system should provide a different perspective for the selection of fusion levels and subsequent surgical success in the treatment of AIS.

\section{MATERIAL and METHODS}

The study included 18 patients with AIS who were scheduled to undergo posterior instrumented spinal fusion at our clinic. An Electronic Traction Table (ETT), internally designed at our clinic, was used to evaluate the radiological and clinical parameters of the spine. A minimum 2-year follow-up period was indicated. Each patient was evaluated physically. Radiographic assessment included preoperative standing posteroanterior (PA) and lateral, supine side bending, supine with ETT and postoperative standing PA and lateral direct radiographs. Sagittal balance was calculated according to thoracic kyphosis (T4-T12), thoracolumbar junction (T12-L2), Lumbar lordosis (L1-L5) using the Cobb method, and frontal balance was calculated based on the line between the central sacral line and $\mathrm{C} 7$ spinous process.

\section{Technique}

The study was based on the use of an ETT, developed internally at our clinic. The device had a digital control panel and mobile segments that can be calibrated individually for each patient before application. The mobile segments applied longitudinal traction and lateral pushing according to the three-point principle. On the digital control panel, the application force was shown in kilograms. A part of the device was motorized with a piston rod that applied the lateral force. The treadles were made of polyurethane and combined with a motor unit. The section that stabilizes the pelvis was of a soft material that allowed mobility. There was a mobile X-ray cassette system made of hard polyurethane that calculated the patient's body weight (Figure 1A, B). Longitudinal traction applied to the patients avoided exceeding $70 \%$ of their body weight. If the patient reported pain during application, traction was released and a lower traction force was applied. The same application was used for the lateral push mechanism and the values were recorded. Lateral pushing was applied to the apical vertebrae of the lumbar curvature and to the costae of thoracic curvatures. For lateral pushing, pain was used as a basic variable. The measure of force being applied at pain onset was recorded in kilograms. At the third stage of the application, both longitudinal traction and lateral pushing radiographs were taken. The entire procedure was performed with the patient in a conscious state. Pain experienced by the patient during the procedure was considered as a limiting factor. At the initial stage of the study, the procedure described was applied to the first 5 patients using the same parameters, but also under general anesthesia. Because the difference between the results was not considered significant, use of general anesthesia for performing the procedure was abandoned for the rest of the study.

The Cobb angles, apical vertebra rotations, stable vertebra, and neutral vertebra were derived from these radiographs. Preoperative bending and ETT radiographs were measured according to Formula 1a (Flexibility rate \%=preoperative standing angle-preoperative bending angle/preoperative angle $X 100 \%$ ), and Formula 1b (Flexibility rate \%=preoperative standing angle-preoperative ETT angle/preoperative angle $\mathrm{X}$ 100\%).

The postoperative correction rate and correction index were calculated according to Formulas $2 \mathrm{a}$ and $2 \mathrm{~b}$ (Correction rate $\%=$ Preoperative angle-postoperative angle/preoperative angle $\mathrm{X} 100$ Correction index $\%=$ Correction rate/Flexibility rate
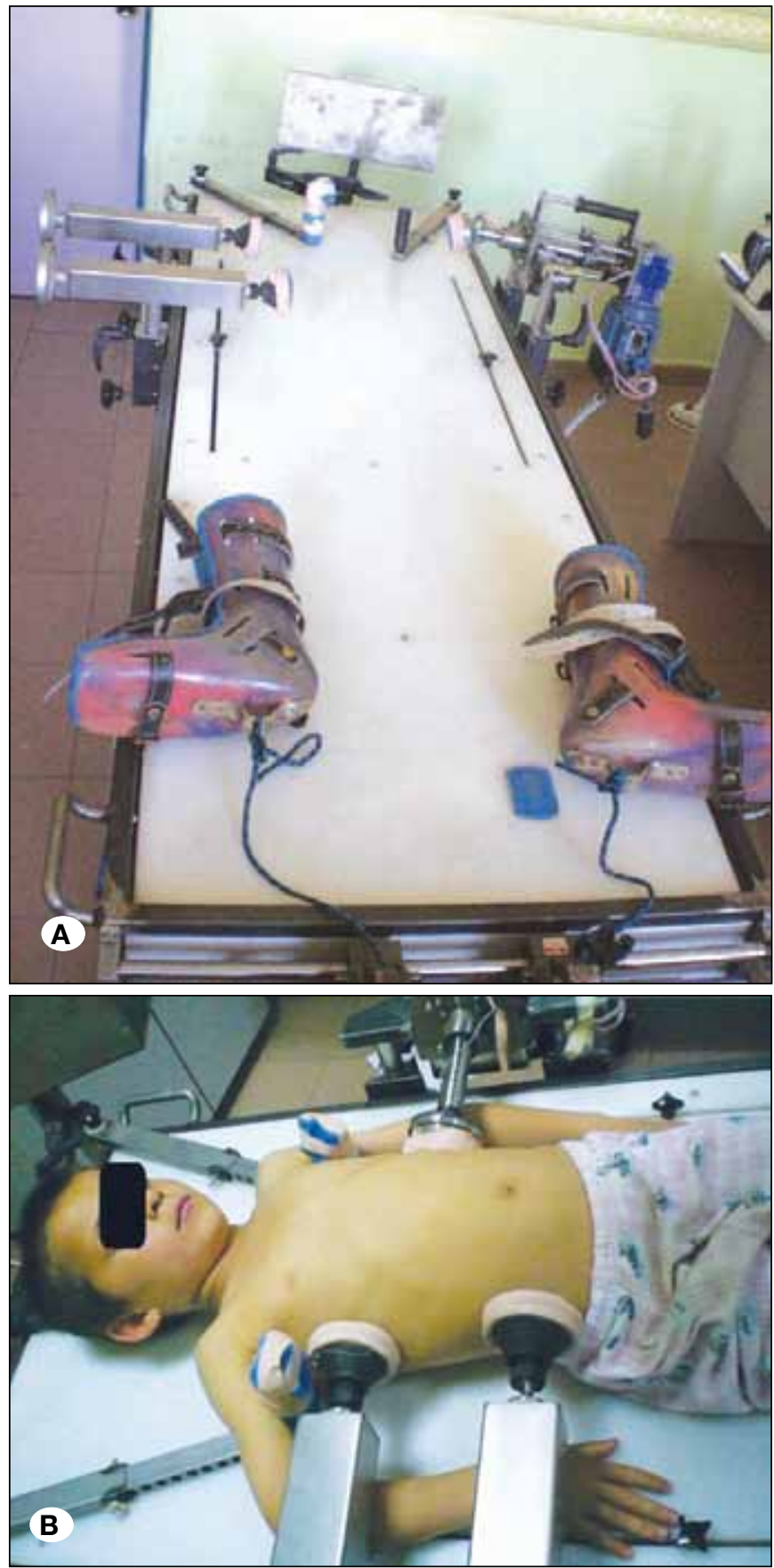

Figure 1: A) Electronic traction table, B) Patient application of electronic traction table. 
$X$ 100). Correction loss was measured at the 2-year followup examination according to Formula 3 (Correction loss =last control angle-postoperative angle/preoperative angle $X 100$ ).

Frontal Cobb Angle (FCA), Bending Cobb Angle (BCA), longitudinal traction Cobb Angle (LTCA), Lateral Push Cobb Angle (LPCA), Longitudinal traction and lateral push Cobb Angle (LTLPCA), postoperative Cobb Angle (PCA), Postoperative 2-year Cobb Angle (PC2A), bending flexibility rate (BFR), Longitudinal traction flexibility rate (LTFR), Lateral push Flexibility rate (LPFR), Longitudinal traction and lateral push flexibility rate (LTLPFR), Correction rate (CR), Bending Correction index $(\mathrm{BCl})$, Longitudinal traction correction index (LTCl), Lateral push correction index (LPCI), Longitudinal traction and lateral push correction index (LTLPCI) were measured.

Statistical analyses were performed using SPSS statistical software version 15.0 (SPSS Inc., Chicago, IL, USA). The Pearson correlation coefficient was calculated using bivariate analyses. Bonferroni multiple comparisons and the Wilcoxon test were used. A value of $p<0.05$ was considered statistically significant.

Table I: Major Cobb Angle Mean Values at Different Positions

\begin{tabular}{ccc}
\hline Major Cobb Angle & Mean & SD \\
\hline FCA & 54.67 & 7.33 \\
\hline BCA & 41.72 & 9.89 \\
\hline LTCA & 35.11 & 7.51 \\
\hline LPCA & 30.89 & 7.19 \\
\hline LTLPCA & 25.39 & 6.55 \\
\hline PCA & 20.67 & 6.42 \\
\hline PC2A & 21.22 & 6.85 \\
\hline
\end{tabular}

\section{RESULTS}

The patient group comprised 13 females and 5 males with an average age at surgery of $14 \pm 1.57$ years. No bracing was used on any of the patients, for all of them had surgeryindicated scoliosis. The maturity was evaluated according to the Tanner classification and the Risser sign. Deformities were classified as Lenke type $1 \mathrm{~A}$ in 10 patients, type $1 \mathrm{~B}$ in 1, type $3 \mathrm{~B}$ in 4, and type $3 \mathrm{C}$ in 3 . All of the structural curvatures were mainly thoracic. The minor curvatures were thoracolumbar/ lumbar curvatures. Patients with minor curvatures on the bending radiographs $<25^{\circ}$ were classified as Lenke type 3 . According to the bending radiographs, all of the Lenke type 3 patients except one decreased to $<25^{\circ}$ on longitudinal and lateral pushing. The major Cobb angles for all application runs are shown in Table I. There was a statistically significant difference between all Cobb angles except PCA and PC2A by the Bonferroni test. There was a strong relationship between $P C A$ and PC2A by the Pearson test $(p=0.000)$. The correlations between BCA, PCA and PC2A were not robust $(p=0.002$ and $=0.008$ ) (Table II). Five different preoperative major Cobb angles in different positions were measured. The significant prescriptive angles between the postoperative angles were the Cobb angles for longitudinal traction and lateral pushing. Five different flexibility ratios were calculated. These flexibility ratios were evaluated with the correction index. Longitudinal traction and lateral pushing angles were more correlated with the correction ratios $(r=0.83, p=0.000)$ (Tables II, III). The mean values for the major Cobb angle correction index are shown in Table IV.

The minor Cobb angle was evaluated in 9 patients who had minor curvatures. No significant difference was determined between the frontal minor Cobb angle, the bending minor Cobb angle and the lateral pushing minor Cobb angle. There was a significant difference between the longitudinal traction minor Cobb angle, the longitudinal traction lateral pushing minor Cobb angle and the postoperative minor Cobb angles.

Table II: The Relations Between Major Cobb Angles at Different Positions

\begin{tabular}{|c|c|c|c|c|c|c|c|}
\hline Major Cobb Angle & FCA & BCA & LTCA & LPCA & LPLTCA & PCA & PC2A \\
\hline FCA & - & & & & & & \\
\hline $\mathrm{BCA}$ & $\begin{array}{c}0.83 \\
(p=0.000)\end{array}$ & - & & & & & \\
\hline LTCA & $\begin{array}{c}0.79 \\
(p=0.000)\end{array}$ & $\begin{array}{c}0.81 \\
(p=0.000)\end{array}$ & - & & & & \\
\hline LPCA & $\begin{array}{c}0.84 \\
(p=0.000)\end{array}$ & $\begin{array}{c}0.81 \\
(p=0.000)\end{array}$ & $\begin{array}{c}0.93 \\
(p=0.000)\end{array}$ & & & & \\
\hline LTLPCA & $\begin{array}{c}0.82 \\
(p=0.000)\end{array}$ & $\begin{array}{c}0.76 \\
(p=0.000)\end{array}$ & $\begin{array}{c}0.83 \\
(p=0.000)\end{array}$ & $\begin{array}{c}0.94 \\
(p=0.000)\end{array}$ & & & \\
\hline PCA & $\begin{array}{c}0.73 \\
(p=0.000)\end{array}$ & $\begin{array}{c}0.67 \\
(p=0.002)\end{array}$ & $\begin{array}{c}0.71 \\
(p=0.001)\end{array}$ & $\begin{array}{c}0.80 \\
(p=0.000)\end{array}$ & $\begin{array}{c}0.89 \\
(p=0.000)\end{array}$ & & \\
\hline PC2A & $\begin{array}{c}0.72 \\
(p=0.000)\end{array}$ & $\begin{array}{c}0.60 \\
(p=0.008)\end{array}$ & $\begin{array}{c}0.68 \\
(p=0.002)\end{array}$ & $\begin{array}{c}0.78 \\
(p=0.000)\end{array}$ & $\begin{array}{c}0.89 \\
(p=0.000)\end{array}$ & $\begin{array}{c}0.98 \\
(p=0.000)\end{array}$ & \\
\hline
\end{tabular}


Table III: Major Cobb Angle Flexibility Ratio Bonferroni Test $p$ Values

\begin{tabular}{cccccc}
\hline Flexibility ratio & BFR & LTFR & LPFR & LTLPFR & CR \\
\hline BFR & - & & & & \\
LTFR & $\begin{array}{c}0.55 \\
(p=0.018)\end{array}$ & - & & & \\
\hline LPFR & $\begin{array}{c}0.51 \\
(p=0.030)\end{array}$ & $\begin{array}{c}0.83 \\
(p=0.000)\end{array}$ & - & & \\
\hline LTLPFR & $\begin{array}{c}0.49 \\
(p=0.037)\end{array}$ & $\begin{array}{c}0.63 \\
(p=0.000)\end{array}$ & $\begin{array}{c}0.88 \\
(p=0.000)\end{array}$ & - & \\
\hline CR & $\begin{array}{c}0.35 \\
(p=0.031)\end{array}$ & $\begin{array}{c}0.47 \\
(p=0.049)\end{array}$ & $\begin{array}{c}0.65 \\
(p=0.004)\end{array}$ & $\begin{array}{c}0.83 \\
(p=0.000)\end{array}$ & - \\
\hline
\end{tabular}

Table IV: Major Cobb Angle Correction Index (\%)

\begin{tabular}{lcc}
\hline Correction Index & Mean & $\begin{array}{c}\text { Standart } \\
\text { deviation }\end{array}$ \\
\hline $\begin{array}{l}\text { Bending Correction Index } \\
(\mathrm{BCl})\end{array}$ & 307 & 129 \\
\hline $\begin{array}{l}\text { Longitudinal traction Correction Index } \\
\text { (LTCl) }\end{array}$ & 183 & 37 \\
\hline $\begin{array}{l}\text { Lateral push Correction Index } \\
\text { (LPCl) }\end{array}$ & 145 & 22 \\
\hline $\begin{array}{l}\text { Longitudinal traction and lateral push } \\
\text { Correction Index (LTLPCl) }\end{array}$ & 116 & 11 \\
\hline
\end{tabular}

Table V: Minor Cobb Angle Flexibility Ratio Bonferroni Test $p$ Values

\begin{tabular}{lccccc}
\hline Flexibility ratio & BFR & LTFR & LPFR & LTLPFR & CR \\
\hline BFR & - & & & \\
\hline LTFR & 0.017 & - & & \\
\hline LPFR & 0.007 & 0.002 & - & & \\
\hline LTLPFR & 0.000 & 0.014 & 0.000 & - & \\
\hline CR & 0.000 & NS & 0.000 & NS & - \\
\hline
\end{tabular}

NS: not significant.

Five different flexibility ratios of the minor Cobb angles were calculated. In the same way as for the major Cobb angle, the longitudinal traction and lateral pushing minor angles were correlated with the correction ratios. There was no difference between the postoperative minor Cobb angle and the 2-year follow-up minor Cobb angle. The minor Cobb angle flexibility ratios were calculated in 5 different positions. According to the variant analyses, there were significant differences between these 5 values (Table V). The significance of difference of the flexibility ratios of the minor Cobb angle was evaluated with the Bonferroni test, and no difference was determined between the minor Cobb angle correction ratio and the
Table VI: Minor Cobb Angle Correction Index (\%)

\begin{tabular}{lcc}
\hline Correction Index & Mean & $\begin{array}{c}\text { Standart } \\
\text { deviation }\end{array}$ \\
\hline $\begin{array}{l}\text { Bending Correction Index } \\
\text { (BCl) }\end{array}$ & 189 & 58 \\
\hline $\begin{array}{l}\text { Longitudinal traction Correction Index } \\
\text { (LTCl) }\end{array}$ & 133 & 77 \\
\hline $\begin{array}{l}\text { Lateral push Correction Index } \\
\text { (LPCl) }\end{array}$ & 591 & 371 \\
\hline $\begin{array}{l}\text { Longitudinal traction and lateral push } \\
\text { Correction Index (LTLPCl) }\end{array}$ & 99 & 29 \\
\hline
\end{tabular}

longitudinal traction minor Cobb angle flexibility ratios. There was also no difference between the longitudinal traction lateral pushing minor Cobb angles flexibility and minor Cobb angle correction ratios. The same values as the major Cobb angles were determined on the lateral pushing radiographs; and the difference was statistically significant. The correction index of the minor Cobb angles was evaluated and a correlation was determined between the longitudinal traction lateral pushing correction index and the bending minor Cobb angle correction index (Table VI).

Values for the stable vertebra, the neutral vertebra, the apex of the curvature and vertebra which was within the curvature were derived from the bending and traction radiographs (Table VII). More mobile segments at proximal and distal levels of the vertebral column were achieved with the traction radiographs than with the bending radiographs. Changing the stable and neutral vertebrae, in particular, made this challenging. An average of 0.6 vertebra levels were saved from the proximal and an average of 1.1 vertebrae were saved at the stable vertebra level. Posterior instrumentation and posterior fusion were applied to all patients. Anterior surgery was not used because there was no major Cobb angle up to $40^{\circ}$ on longitudinal traction and lateral pushing. There were no neurological complications. Only one superficial infection occurred. 
Table VII: Parameters of All Patients

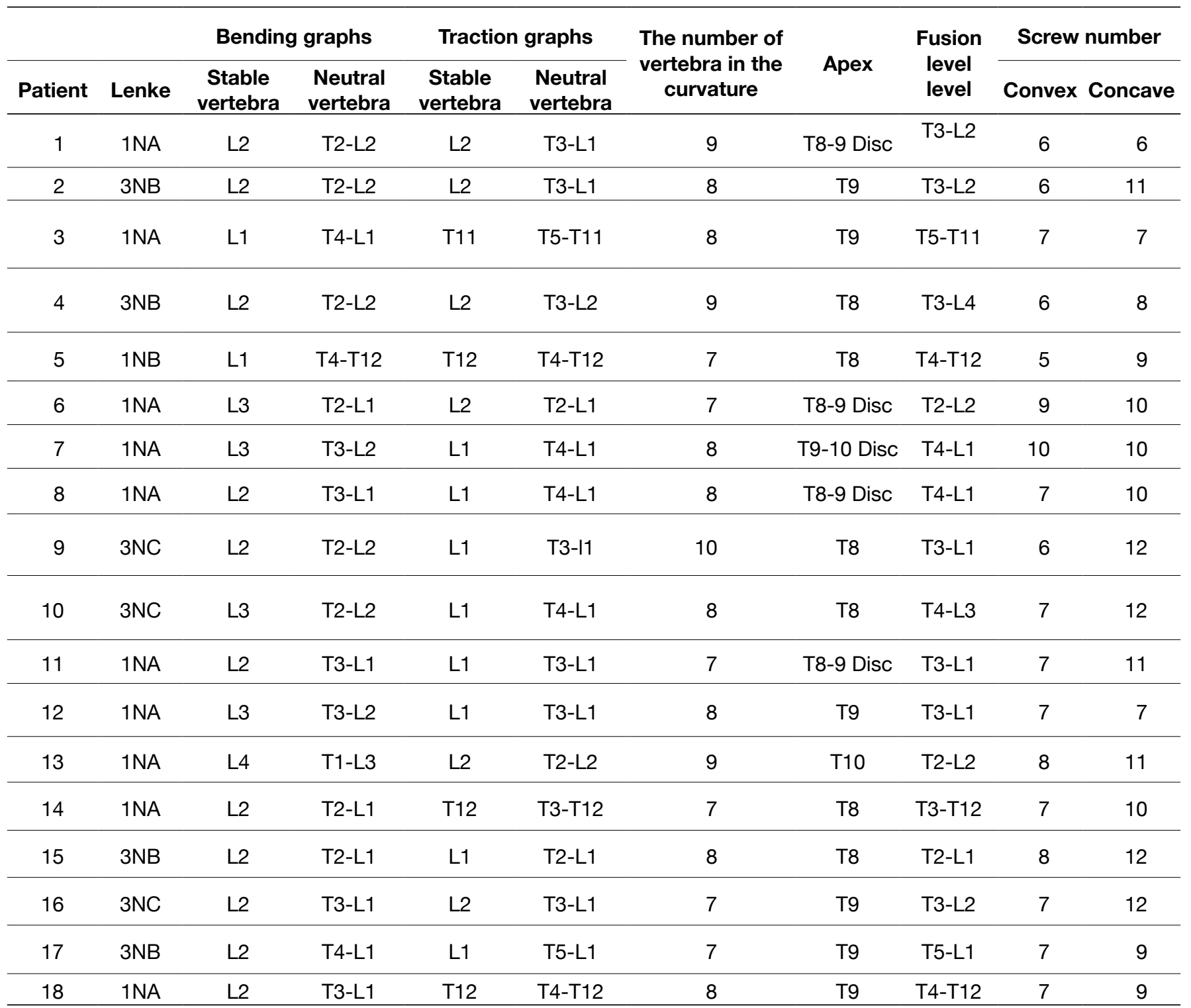

\section{DISCUSSION}

Adolescent idiopathic scoliosis is the most common form of scoliosis (26). The female to male ratio is $8 / 1$ in adolescent idiopathic scoliosis. In this study, the ratio of females to males was 2.6/1.

The goal of surgical management is to select fusion levels (13), and classification systems have been developed to overcome this problem. In this study, the Lenke classification system was used and $61.1 \%$ of the patients were Lenke type 1 and $38.9 \%$ Lenke type 3 . The most controversial aspect of scoliosis surgery is the selection of the fusion levels. The aim of the treatment is to obtain sagittal and frontal balance with minimal fusion levels (9). Flexibility is an important consideration for the selection of fusion levels. Preoperative side-bending films, traction films and push-prone films are used for evaluating fusion levels $(7,10,12,15,22,24)$. The selection of distal levels may prevent the patient from spinal decompensation and adding-on phenomenon (20). In a study by Ni et al. (14), sidebending radiographs were used to determine the distal fusion level with single thoracic curvatures. This method was shown to be effective in the preservation of lumbar motion segments. Takahashi et al. also used bending radiographs to select the optimal lowest vertebrae for selective thoracic fusion in Lenke Type 1B, 1C and Type 3C (21). In this study, the electronic traction table was used to determine the fusion levels. The flexibility and fusion level values in the current study were significantly different from the lateral bending radiographs. The development of modern screw constructs, in particular, provides more powerful corrective forces (14). Therefore, these corrective forces on the lateral bending radiographs are not sufficient to determine distal and proximal fusion levels. 
Using the electronic traction table could help to show a higher correction index, more than with other techniques.

Traction radiographs have been used to determine flexibility in many studies. Hirsch et al. used the suspension test to determine flexibility and fusion levels (5). It was emphasized that a low dose technique with suspension avoided radiation of the traction radiographs. Vaughan et al. suggested using traction radiographs in curvatures of $>60^{\circ}$ and showed that it was more useful than bending radiographs in the determination of stable vertebrae. It was reported that using traction radiographs $<60^{\circ}$ may result in the wrong stable vertebra and wrong fusion levels being selected, which in turn may lead to the adding-on deformity and decompensation postoperatively (23). In the current study, an average of 1.1 vertebrae were excluded from the fusion level when determined by the electronic traction table, rather than by lateral bending. The major Cobb angle values were evaluated both above and below $60^{\circ}$ and longitudinal traction and lateral pushing were more prescriptive than bending radiographs for postoperative correction. When longitudinal traction lateral pushing radiographs were compared with bending radiographs, significant differences were seen between the major Cobb angles, minor Cobb angles, flexibility ratios, correction ratio and correction index values. On the other hand, the strongest correlation with postoperative correction was longitudinal traction and lateral pushing radiographs. The electronic traction table radiographs presented here can be defined as a new method that can be used with visible force application and can be applied independently of the patient.

Hamzaoglu et al. suggested using traction radiographs in general anesthesia in all curvature types. The use of bending and fulcrum radiographs was reported to be appropriate in serious lumbar curvatures. That study had a limitation regarding patient data before the surgery. In the current study, the correction ratio was estimated before the operation and accurate information could be given to the patient's family (4). White and Panjabi stated that if the major Cobb angle was $>53^{\circ}$, longitudinal traction would be best but if it is $<53^{\circ}$, lateral pushing would be the best method for curve correction (27). In the current study, both techniques were used for correction and the results achieved were close to the operative correction. Watanabe suggested that if the apex of the main thoracic curvature was higher than the T9 vertebra, bending radiographs would be better than traction radiographs. In the same study, the same suggestion was made for thoracolumbar/lumbar curvatures. In this study, the apexes of all the curvatures were found to be higher than T9 in all but 2 patients. Nevertheless, the traction radiographs were better than the bending radiographs. The same results were also determined in minor curvatures (25). Another important point of the study by Watanabe was the number of vertebrae included in the main thoracic curvature. If the number of vertebrae is more than $6-7$, then bending radiographs are better than traction and conversely, if the number of vertebrae is lower, traction radiographs would give better results than bending radiographs. In the current study, although the mean number of vertebrae included in the curvature was 7.9, traction radiographs were better than bending radiographs.
In a study by Potter et al., better results with posterior fusion than with anterior fusion were reported in Lenke type 1 curvature treatment (16). Puno et al. reported that selective fusion was a good choice for Lenke type 1 curvatures. In the current study, there were 11 Lenke type 1 and 7 Lenke type 3 patients based on the bending radiographs (17). When the patients were evaluated according to the electronic traction table radiographs, 2 patients could be classified as Lenke type 3 scoliosis. These 2 patients underwent surgery with posterior instrumentation and posterior fusion. Posterior instrumentation and selective fusion were applied to the other 16 patients. The postoperative results of the current study were similar to those reported in the literature.

An unexpected aspect of this study was the effect of lateral pushing on minor curvatures. Lateral pushing alone did not decrease minor curvature values in the same way as longitudinal traction and it was not successful for flexibility evaluation. The force that was applied to the apex of the major curvature can be considered to have had a disruptive effect on the minor curvature.

\section{- CONCLUSION}

Adolescent idiopathic scoliosis is a 3-dimensional spinal deformity. A useful technique is required to balance both tractional and rotational forces to evaluate flexibility before the operation. The electronic traction table is a new device for determining preoperative flexibility with longitudinal traction and lateral pushing radiographs. The results of this study show that it could be useful when choosing selective fusion levels at the proximal and distal ends of the vertebral column. This would enable the surgeon to give correct information about the surgery and fusion levels to patient and relatives.

\section{REFERENCES}

1. Büchler $P$, de Oliveria $M E$, Studer $D$, Schuman $S$, Zheng G, Scneider J, Hasler CC: Axial suspension test to assess pre-operative spinal flexibility in patients with adolescent idiopathic scoliosis Eur Spine J 23 (12):2619-2625, 2014

2. Chen ZQ, Wang CF, Bai YS, Zhu XD, Yang CW, Xie Y, Li M: Using precisely controlled bidirectional orthopedic forces to assess flexibility in adolescent idiopathic scoliosis: Comparisons between push-traction film, supine side bending, suspension, and fulcrum bending film. Spine (Phila $\mathrm{Pa} 1976$ ) 36:16791684,2011

3. Erickson MA, Baulesh DM: Lowest instrumented vertebra selection in AIS. J Pediatr Orthop 31:S69-76, 2011

4. Hamzaoglu A, Talu U, Tezer M, Mirzanli C, Domanic U, Goksan SB: Assessment of curve flexibility in adolescent idiopathic scoliosis. Spine (Phila Pa 1976) 30:1637-1642, 2005

5. Hirsch C, Ilharreborde B, Mazda K: EOS suspension test for the assessment of spinal flexibility in adolescent idiopathic scoliosis. Eur Spine J 24:1408-1414, 2015

6. Ilharreborde B, Even J, Lefevre Y, Fitoussi F, Presedo A, Souchet P, Penneçot GF, Mazda K: How to determine the upper level of instrumentation in Lenke type 1 and 2 adolescent idiopathic scoliosis: A prospective study of 132 patients. J Pediatr Orthop 28:733-739, 2008 
7. Kleinman R, Csongradi J, Rinsky L, Bleck EE: The radiographic assessment of spinal flexibility in scoliosis: A study of the efficacy of the prone push film. Clin Orthop 162:47-53, 1982

8. Lamarre ME, Parent S, Labelle H, Aubin CE, Joncas J, Cabral A, Petit Y: Assessment of spinal flexibility in adolescent idiopathic scoliosis: Suspension versus side-bending radiography. Spine (Phila Pa 1976) 34: 591-597, 2009

9. Large DF, Doig WG, Dickens DR, Torode IP, Cole WG: Surgical treatment of double major scoliosis. Improvement of the lumbar curve after fusion of the thoracic curve. J Bone Joint Surg $\mathrm{Br}$ 73:121-124, 1991

10. Lenke LG, Betz RR, Clements D, Merola A, Haher T, Lowe T, Newton P, Bridwell KH, Blanke Kl: Curve prevalence of a new classification of operative adolescent idiopathic scoliosis: Does classification correlate with treatment? Spine (Phila Pa 1976) 27(6):604-611, 2002

11. Lenke LG, Betz RR, Harms J, Bridwell $K H$, Clements $D H$, Lowe TG, Blanke K: Adolescent idiopathic scoliosis: A new classification to determine extent of spinal arthrodesis. J Bone Joint Surg Am 83-A: 1169-1181, 2001

12. Luk KD, Cheung KMC, Lu DS, Leong JC: Assessment of scoliosis correction in relation to flexibility using the fulcrum bending correction index. Spine (Phila Pa 1976) 23:23032307, 1998

13. Moe $\mathrm{JH}$ : A critical analysis of methods of fusion for scoliosis: An evaluation in two hundred and sixty-six patients. J Bone Joint Surg Am 40:529-554, 1958

14. Ni HJ, Su JC, Lu YH, Zhu XD, He SS, Wu DJ, Xu J, Yang CW, Wang CF, Zhao YC, Li M: Using side-bending radiographs to determine the distal fusion level in patients with single thoracic idiopathic scoliosis undergoing posterior correction with pedicle screws. J Spinal Disord Tech 24:437-443, 2011

15. Polly D, Sturm P: Traction versus supine side-bending: Which technique best determines curve flexibility? Spine (Phila $\mathrm{Pa}$ 1976) 23:804-808, 1998

16. Potter BK, Kuklo TR, Lenke LG: Radiographic outcomes of anterior spinal fusion versus posterior spinal fusion with thoracic pedicle screws for treatment of Lenke type I adolescent idiopathic scoliosis curves. Spine (Phila Pa 1976) 30: 1859-1866, 2005

17. Puno RM, An KC, Puno RL, Jacob A, Chung SS: Treatment recommendations for idiopathic scoliosis: An assessment of the Lenke classification. Spine (Phila Pa 1976) 28:2102-2114, 2003
18. Reames DL, Smith JS, Fu KM, Polly DW Jr, Ames CP, Berven $\mathrm{SH}$, Perra JH, Glassman SD, Mc Carthy RE, Knapp RD Jr, Heary R, Shaffrey Cl; Scoliosis Research Society Morbidity and Mortality Committee: Complications in the surgical treatment of 19.360 cases of pediatric scoliosis: A review of the Scoliosis Research Society Morbidity and Mortality database. Spine (Phila Pa 1976) 36:1484-1491, 2011

19. Singla A, Bennett JT, Sponseller PD, Pahys JM, Marks MC, Lonner BS, Newton PO, Miyanji F, Betz RR, Cahill PJ, Samdani AF: Results of selective thoracic versus non selective fusion in Lenke type 3 curves. Spine (Phila Pa 1976) 39(24):2034-2041, 2014

20. Suk SI, Lee SM, Chung ER, Kim JH, Kim SS: Selective thoracic fusion with segmental pedicle screw fixation in the treatment of thoracic idiopathic scoliosis: More than 5- year follow-up. Spine (Phila Pa 1976) 30:1602-1609, 2005

21. Takahashi J, Newton PO, Ugrinow VL, Bastrom TP: Selective thoracic fusion in adolescent idiopathic scoliosis. Spine (Phila Pa 1976) 36:1131-1141, 2011

22. Torell G, Nachemson A, Haderspeck-Grib K, Schultz A: Standing and supine Cobb measures in girls with idiopathic scoliosis. Spine (Phila Pa 1976) 10:425-427, 1985

23. Vaughan JJ, Winter RB, Lonstein JE: Comparison of the use of supine bending and traction radiographs in the selection of the fusion area in adolescent idiopathic scoliosis. Spine 21: 2469-2473, 1996

24. Vedantam R, Lenke L, Bridwell K, Lindville DL: Comparison of push-prone and lateral-bending radiographs for predicting postoperative coronal alignment in thoracolumbar and scoliotic curves. Spine (Phila Pa 1976) 25:76-81, 2000

25. Watanabe K, Kawakami N, Nishiwaki Y, Goto M, Tsuji T, Obara T, Imagama S, Matsumoto M: Traction versus supine sidebending radiographs in determining flexibility: What factors influence these techniques? Spine (Phila Pa 1976) 32(23): 2604-2609, 2007

26. Weinstein SL, Dolan LA, Spratt KF, Peterson KK, Spoonamore MJ, Ponseti IV: Health and function of patients with untreated idiopathic scoliosis: A 50-year natural history study. JAMA 289:559-567, 2003

27. White AA, Panjabi MM: Practical biomechanics of scoliosis and kyphosis. In: White AA, Panjabi MM, (eds). Clinical Biomechanics of the Spine, 2nd ed. Philadelphia: Lippincott,1990:138-143 